\title{
Quality control in bacteriology: preliminary trials ${ }^{1}$
}

\author{
E. JOAN STOKES AND J. L. WHITBY2 \\ From University College Hospital, London, and Queen Elizabeth Hospital, Birmingham
}

SYNOPSIS Six trials of quality control material sent in the form of artificial specimens are reported. A method of assessment using a computer for complex results, including antibiotic sensitivity tests, was employed. The trials were successful in showing the need for a comprehensive service and in bringing to light by this method a wide variety of errors.

If diagnostic laboratories are to maintain a high standard, quality control is essential. In chemical pathology and haematology it is already routine practice but in bacteriology test material is not readily available. Ampoules of dried cultures to check tests of identification can be purchased but are seldom employed because identification is only one of the many problems which face the diagnostic bacteriologist. Indeed when a potential pathogen has been isolated in pure culture half the battle is won.

If positive test material as close as possible to the specimens undergoing investigation were available for repeated tests throughout the year, it would enable bacteriologists to check their procedures and faulty methods of isolation as well as of identification would be disclosed.

The possibility of obtaining commercially prepared material in this form was investigated but was found to be impracticable and the alternatives are either to set up a separate quality control laboratory to manufacture 'specimens' or for the task to be undertaken by one or more practising laboratories; tests using the latter alternative are reported here. It has the advantage that the manufacturing laboratory has problems common to users of the service and can test its own materials under field conditions. Moreover suitable material for specimens is to hand and the strains sent out can be freshly isolated and are therefore likely to be nearer in their growth requirements and behaviour to wild strains.

'Other participants: Blowers, R., Bradley, J. M., Brumfitt, W., Crone, P. B., Cunliffe, A. C., Darrell, J. H., Dowsett, L. M., Furniss, A. L., Greenbury, C. L., Gruneberg, R. N., Hughes, M. H., Hurley, R., Hutchison, J. G. P., Jebb, W. H. H., Kingsley Smith, A. J., McCoy, M. H., Meers, P. D., Mohun, A. F., Mortimer, P. R., Speller, D. C. E., Taylor, C. E. D., Turner, G. C., Williams, R. E. O., and Willis, A. T. 'Present address: Department of Bacteriology and Immunology, University of Western Ontario, London, Canada.

Received for publication 4 October 1971.
These trials were made by a group of laboratories in various parts of England, whose directors were interested in establishing a regular service, in order to test the proposed methods of manufacture of 'specimens' and assessment of results and to estimate the cost. They were financed by the Department of Health. Participants were 13 public health laboratories, eight laboratories linked with teaching hospitals, and four non-teaching hospital laboratories (five in the last three trials). One of the teaching hospital laboratories which had previous experience in the ACP Sensitivity Test Trial (Association of Clinical Pathologists, 1965) sent the specimens and took part in the trial by posting a sample box to itself; another teaching hospital laboratory, experienced in computer techniques, received the results from all laboratories.

Regular testing is essential in quality control and participating laboratories gain more from the tests if they can compare their results with others examining similar material sent out at the same time. For this reason and because preparation in batches at regular intervals is less disturbing to working routine than test material on demand, 'specimens' were sent at approximately monthly intervals on three occasions, followed by an interval for assessment and then a further three trials. In order to give laboratories the same kind of information they should normally receive the 'specimens' were said to have come from appropriate sites, but no attempt was made to disguise them as anything other than quality control, nor do we regard this as necessary.

\section{Methods}

MANUFACTURE OF SPECIMENS

Six specimens were sent for each trial (three faeces, two swabs in transport medium, and one urine). 


\section{Faeces}

Faeces sent for occult blood estimation from patients not receiving antibiotics was emulsified in about five times its volume of peptone water in an electric homogeniser. It was then distributed in $2 \mathrm{ml}$ volumes, refrigerated overnight, and seeded on the day of dispatch with 2 drops, $0.04 \mathrm{ml}$, of diluted overnight culture of an intestinal pathogen. The culture was counted at the time of seeding by the Miles and Misra method so that the approximate number of viable pathogens per millilitre faeces suspension could be calculated. The aim was to grade the specimens so that one sample should yield a positive result on primary plates and one only after enrichment, the third being intermediate between them. The numbers of pathogens seeded per $\mathrm{ml}$ faeces suspension were $10^{6}-10^{7}$ for the strong samples, $10^{4}-10^{5}$ for the intermediate samples, and $10^{2}-10^{3}$ for the weak samples.

Tests on extra samples of the faecal specimens sent in trials 4 and 6 were also made by three of the participating laboratories knowing with what they had been seeded. Good survival of Salmonella was demonstrated. It could be isolated from specimens kept at room temperature for at least two weeks, There was growth of Salmonella initially at room temperature (approximately $22^{\circ} \mathrm{C}$ ) in samples heavily seeded at the expense of the normal commensals.

The possibility of using a suspending medium resembling faeces instead of the natural material has been considered, and in the fifth trial a sterile yeast suspension kindly supplied by Oxoid Limited as employed for the Chick-Martin test was used. This was seeded with $S h$. sonnei in the same manner as the previous samples and to simulate natural conditions 3 drops of a peptone water culture of $E$. coli and 2 drops of diluted culture of Proteus miribilis were added to the suspension before seeding with the pathogen, all bottles receiving the same amount of commensals. The results were disappointing since few laboratories were able to isolate the pathogen. This was probably because too much commensal was added which overwhelmed the pathogen in many cultures. Even if it were proved that this Shigella was abnormal and that most pathogens would survive in the yeast suspension, there are disadvantages in the method. If a natural specimen is to be simulated commensal organisms must be added and it would be necessary either to use stock tested strains or to do preliminary tests with freshly isolated commensals before preparing material for each trial. Moreover, one could not hope to cover the variety of strains of different commensals in natural faeces and if selective media are to be improved in the light of results from many laboratories testing these 'specimens' over a long period one would be in danger of suiting media to an artificial set of circumstances.

\section{Swabs}

Swabs were dipped in a $1 / 10$ dilution of overnight broth cultures of the pathogens and then placed in transport medium. When a mixed culture was sent the mixture was prepared and well mixed immediately before dipping.

Tests made at the end of the trials showed that the extra staphylococci occasionally reported may have been due to contamination from the hands of the person introducing the swab into the transport medium while breaking off the swab stick.

Normal urine was brought to the boil to kill contaminating organisms. After distribution in $2 \mathrm{ml}$ volumes it was seeded with 1 drop overnight culture per bottle. In the last three trials sterile peptone water was used instead of urine.

In the first five trials the pathogens inoculated into the 'specimens' were sent in pure culture to the Queen Elizabeth Hospital, Birmingham, and to Hammersmith Hospital, London, where their identity and antibiotic sensitivity was checked and agreed with the distributing laboratory.

\section{METHODS OF ASSESSMENT}

The results of the first three trials were assessed without computer aid. At the end of the third trial it was considered desirable that an extension be considered, unfortunately funds, for instance, for assessing laboratory performance in all bacteriology laboratories in a region were not available, so it was proposed to repeat the trial with the same participants, to try to discover something about methods employed and to experiment with the use of computer facilities for a more rapid analysis and printout of the results.

The computer aspects were dealt with by sending each participating laboratory punch cards in which their laboratory number had been punched and with allotted spaces for entry of results similar to those described (Whitby and Blair, 1970) for routine laboratory working (Fig. 1). On receipt of completed cards the recorded findings were punched into the same cards and fed to the computer, which produced in tabulated form a complete printout of all laboratories findings and a summary (Fig. 2). The tables were photocopied and then sent to all participants. Little difficulty was experienced with using the cards save that they were unsuitable for one of the samples submitted, where more sophisticated tests for antibiotic sensitivity required recording. Faecal specimens were not included in the computer process. 

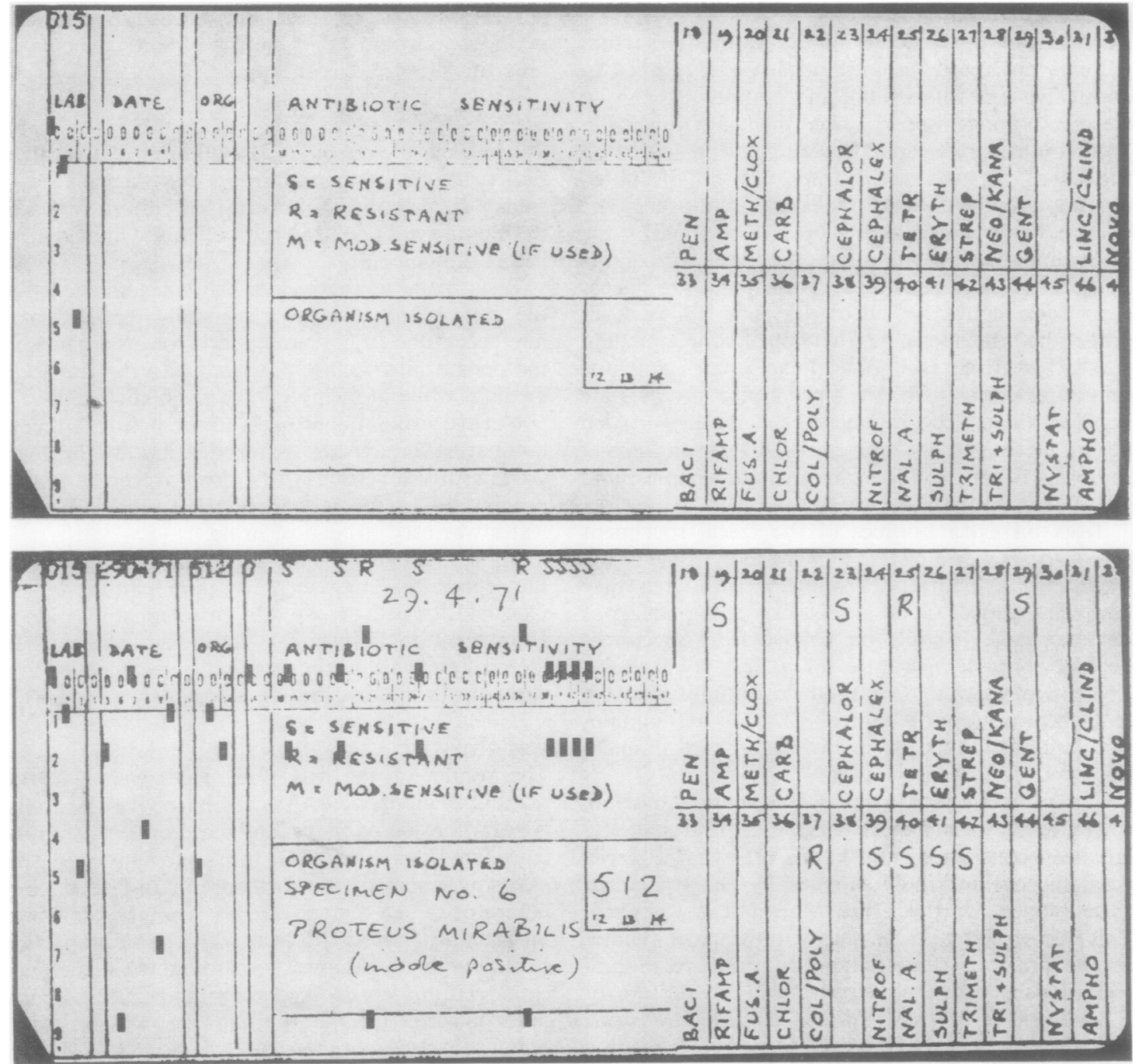

Fig. 1 Punch cards sent to participants before and after completion.

\section{Results}

\section{FAECAL SPECIMENS}

Three specimens of faeces were included in each trial. These consisted of graded numbers of a Salmonella species as outlined in the Methods section. In trial 2 an unseeded sample was included and the weakest seeding omitted and in trial 5 Shigella sonnei was submitted in yeast suspension. Excluding the results for trial 5, where the suspension proved unsuitable, the performance of laboratories showed considerable improvement in the later trials. Thus, in trials 1 and 3, 54 negative and 93 positive reports were received.

Thirty-three of the 54 negative reports were from the samples containing the least numbers of salmonella $N$ and 21 were from samples where Salmonella was present in considerable numbers. In trials 4 and 6 , 22 negative and 122 positive reports were received, 18 of the 22 negative reports being from the samples that contained the least numbers of salmonella. Table I sets out the relative performance in trials 4 and 6 compared with trials $1-3$, and also the performance of public health laboratories and hospital laboratories. Although public health laboratories had performed better in the first trials this no longer appeared to be the case and did N N

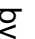
$\stackrel{0}{\subset}$ $\stackrel{\Phi}{\infty}$ $+$ $\frac{0}{0}$ $\frac{8}{8}$ $\frac{\rho^{\circ}}{(1)}$ 


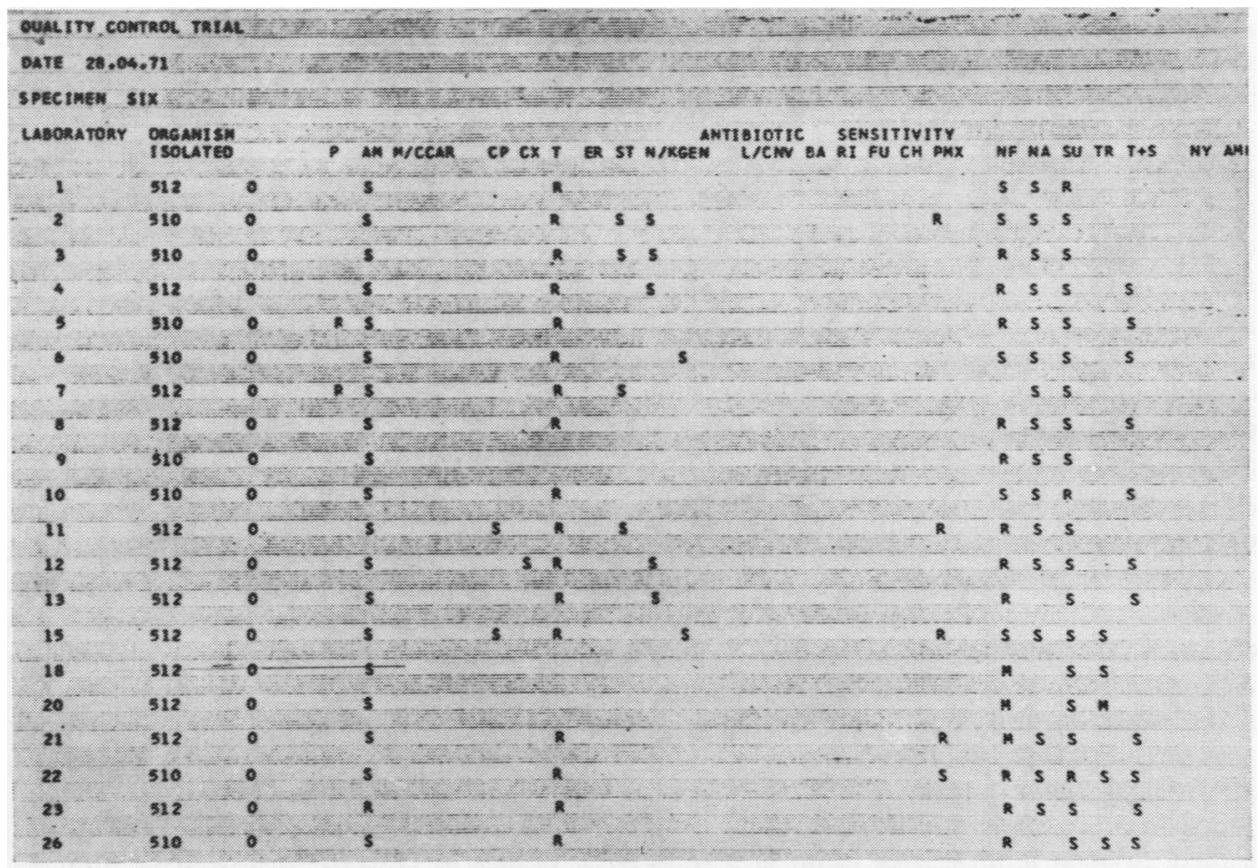

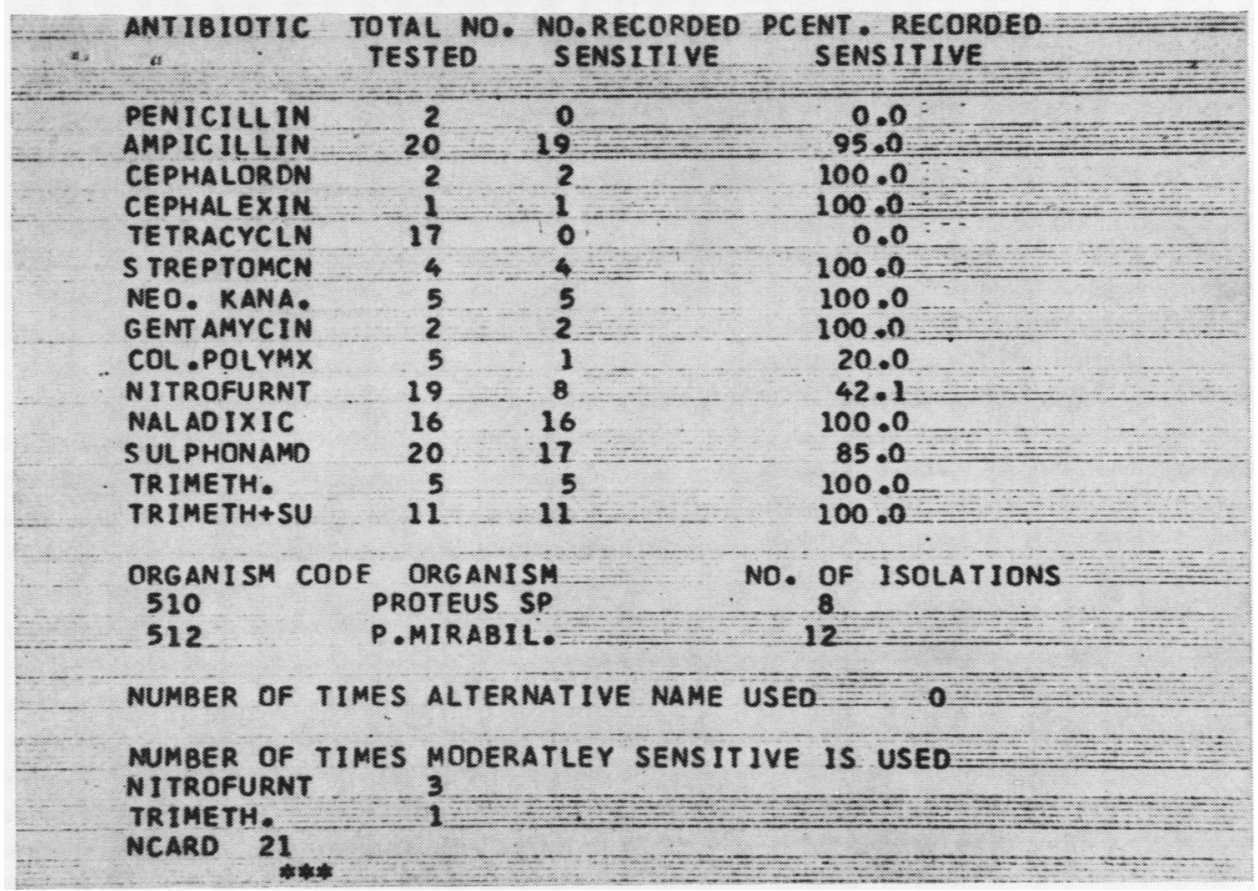

Fig. 2 Computer printout (detail and summary). 


\begin{tabular}{|c|c|c|c|c|c|}
\hline \multicolumn{3}{|l|}{ Trials $1-3^{1}$} & \multicolumn{3}{|l|}{ Trials 4 and $6^{2}$} \\
\hline $\begin{array}{l}\text { Number of Failures } \\
\text { ( } 8 \text { positive samples } \\
\text { per laboratory) }\end{array}$ & $\begin{array}{l}\text { Public Health Service } \\
\text { Laboratories }\end{array}$ & $\begin{array}{l}\text { Hospital } \\
\text { Laboratories }\end{array}$ & $\begin{array}{l}\text { Number of Failures } \\
\text { ( } 6 \text { positive samples } \\
\text { per laboratory) }\end{array}$ & $\begin{array}{l}\text { Public Health Service } \\
\text { Laboratories }\end{array}$ & $\begin{array}{l}\text { Hospital } \\
\text { Laboratories }\end{array}$ \\
\hline 0 & 5 & 0 & 0 & 7 & 4 \\
\hline 1 & 3 & 1 & 1 & 3 & 5 \\
\hline 2 & 0 & 2 & 2 & 0 & 4 \\
\hline 3 & 0 & 2 & 3 & 2 & 1 \\
\hline 4 & 3 & 5 & 4 & 0 & 0 \\
\hline 5 & 1 & 3 & 5 & 0 & 0 \\
\hline
\end{tabular}

Table I Number of times laboratories failed to isolate Salmonella spp from positive samples in the two halves of the trial

${ }^{1}$ One public health and two hospital laboratories failed to report.

One hospital laboratory failed to report.

perhaps represent improved performance in hospital laboratories.

ISOLATION AND IDENTIFICATION OF BACTERIA FROM SWABS AND 'URINE'

No difficulty in the isolation and identification of Staph. aureus, E. coli, Proteus, or Pseudomonas was encountered. In trial 2, two strains of Staph. aureus were included in one sample and this sample was not well handled. Sixteen laboratories found a single strain, eight two strains, and one three strains. In trial $3 \mathrm{Cl}$. welchii was included with Staph. aureus in a swab said to have come from a compound fracture caused by a road traffic accident. Two laboratories of 24 failed to isolate the anaerobe and one other failed to identify it correctly. In trial 6 Cl. welchii was sent alone on a swab said to have come from the uterus of a patient with septic abortion. Four laboratories failed to isolate it although subsequent tests with this strain showed it to be viable in transport medium for at least three days. On this occasion all those isolating it identified it correctly.

Klebsiella aerogenes was sent in urine in trial 6. Correct identification was reported by nine laboratories, Klebsiella species by seven, Klebsiella pneumoniae by one, Enterobacter species by one, and five falsely reported Escherichia coli.

Out of 409 isolations of seven species there were only nine incorrect identifications. Nomenclature varied and some laboratories identified as far as the genus only, especially for urinary pathogens.

\section{ANTIOBIOTIC SENSITIVITY TEST RESULTS}

It was to be expected that more difficulty would be encountered in testing some antibiotics than others. Most of the errors reported in the A.C.P. Antibiotic Sensitivity Test Trial (1965) occurred in tests of penicillinase-producing staphylococci with penicillin which were falsely reported sensitive and false reports of resistance to sulphonamide. Also Proteus mirabilis was sometimes falsely reported sensitive to nitrofurantoin. These errors were again most commonly made and in addition some laboratories had difficulty in recognizing methicillin resistance of Staph. aureus and carbenicillin sensitivity of Pseudomonas aeruginosa which were not previously tested.

In these trials penicillinase-producing Staph. aureus was reported penicillin sensitive eight times in 184 tests. Resistance to sulphonamide was wrongly reported 25 times in 128 tests of urinary pathogens. In 13 of 39 tests Proteus mirabilis was reported sensitive to nitrofurantoin although the minimal inhibitory concentration of the two strains sent out was greater than $128 \mu \mathrm{g}$, that of the sensitive $E$. coli control being $16 \mu \mathrm{g}$ per ml. The results for methicillin sensitivity of Staph. aureus are seen in Table II.

\begin{tabular}{llll}
\hline Trial & $\begin{array}{l}\text { No. of Tests } \\
\text { Reported }\end{array}$ & $\begin{array}{l}\text { No. Reported } \\
\text { Sensitive }\end{array}$ & $M I C^{1}(\mu \mathrm{g} / \mathrm{ml})$ \\
\hline 1 & 21 & 4 & 64 \\
3 & 19 & 4 & $>64$ \\
4 & 22 & 0 & $>64$ \\
6 & 23 & 2 & $>64$ \\
& & & Control 1 \\
\hline
\end{tabular}

Table II Individual laboratory reports of sensitivity of methicillin-resistant Staph. aureus

${ }^{1}$ Plate dilution technique with heavy inoculum, Oxford staphylococcus control.

Carbenicillin sensitivity of Pseudomonas is not easy to determine because the species is never very sensitive although it is treatable by large doses of this penicillin. It is, however, essential that laboratories should be able to distinguish between strains which are treatable and those which are too highly resistant to respond. The same sensitive strain was sent on two occasions in trials 3 and 5. There were nine reports of resistance out of 44 tests, eight of them occurring in trial 3 . The improvement was probably the result of discussion among the parti- 
cipants at the end of the first three trials about the meaning of resistance in this species and the recommendation that a sensitive Pseudomonas should be tested in parallel (Waterworth, 1969). No difficulty was encountered with gentamicin tests.

Streptococcus faecalis is notoriously difficult to test to penicillins (College of Pathologists of Australia, 1968). A strain recently isolated from a blood culture happened to be available and was sent in trial 5. The results are seen in Table III.

\begin{tabular}{lrllll}
\hline & Sensitive & $\begin{array}{l}\text { Moderately } \\
\text { Sensitive }\end{array}$ & Resistant & \multicolumn{2}{l}{$M I C(\mu \mathrm{g} / \mathrm{ml})^{1}$} \\
\cline { 4 - 6 } & & & \multicolumn{3}{c}{$\begin{array}{l}\text { Strept. } \\
\text { faecalis }\end{array}$} \\
\hline Penicillin & 2 & 3 & 19 & 1.0 & 0.03 \\
Ampicillin & 19 & 4 & 1 & 1.0 & 0.06 \\
\hline
\end{tabular}

Table III Reporting of sensitivity of Strept. faecalis to penicillins by 24 laboratories

${ }^{1}$ Plate dilution technique Oxford staphylococcus control

In trial 6 the strain of Klebsiella was moderately resistant to a number of antibiotics but deemed treatable with higher dosage. Scoring errors would be difficult but Table IV sets out the findings of the various laboratories for six antibiotics; there are marked differences but the findings would not indicate overreporting of ampicillin sensitivity (cf Table III).

No attempt has been made to score the total number of errors in examination of swabs and urine because in some of the samples scoring becomes too arbitrary, nor has any attempt been made to compare one laboratory with another, and the results have been returned to laboratories for their own comments and action.

\section{LABORATORY METHODS}

While with faeces there does seem to have been a significant improvement in performance in the later three trials, it would be hard to conclude that there had been much change with antibiotic sensitivity testing since the number of laboratories reporting discrepant results remained much the same. In an attempt to examine some of the reasons for discrepant findings in sensitivity tests a short questionnaire was circulated to participating laboratories; unfortunately, because of a desire not to ask a leading question, the answer to the degree to which testing was controlled did not emerge clearly for all laboratories.

The use of control organisms was mentioned by seven laboratories, queried by one, and not mentioned by the other 16 . Individual discs were the most popular method for applying antibiotics to the plate, being used exclusively in eight laboratories and for part of the routine by a further 12 . Twelve laboratories used Multodiscs and four impregnated rings. Oxoid DST with or without the addition of lysed blood was the most popular medium for testing antibiotic sensitivity routinely. Special conditions to determine methicillin sensitivity (Hewitt, Coe, and Parker, 1969) were used in 21 out of 24 laboratories. Table $\mathrm{V}$ summarizes the amount of antibiotic in micrograms incorporated in the discs or rings for sensitivity testing.

Table VI shows the number of laboratories performing direct sensitivity tests on swabs. The point of the question was to relate it to the findings in trial 2, question 5, where, when two strains of Staph. aureus were submitted on a single swab, only nine out of 25 laboratories submitting answers found both organisms; seven of these performed direct tests routinely and two sometimes did so.

Table VII outlines the methods employed in participating laboratories for faeces. It can be seen that the only discrepancies are in the number of laboratories using additional methods. It is notable how many laboratories do not check the efficiency of fresh batches of culture medium but there was no correlation between this fact and laboratory performances. Three laboratories which successfully isolated salmonella from all specimens did not use any control procedure. Nor again did laboratories picking a single example of each colonial type fare

\begin{tabular}{|c|c|c|c|c|c|c|}
\hline \multirow[t]{2}{*}{ Antibiotic } & \multicolumn{4}{|l|}{ Report } & \multicolumn{2}{|c|}{$M I C(\mu g / m l)$} \\
\hline & Sensitive & $\begin{array}{l}\text { Moderately } \\
\text { Sensitive }\end{array}$ & Resistant & Not Tested & $\begin{array}{l}\text { Kleb. } \\
\text { aerogenes }\end{array}$ & $\begin{array}{l}\text { Sensitive } \\
\text { Control E. coli }\end{array}$ \\
\hline Ampicillin & 4 & 7 & 14 & 0 & 16 & 4 \\
\hline Cephalosporins & 7 & 1 & 0 & 17 & $8^{1}$ & $2^{1}$ \\
\hline Sulphonamide & 17 & 2 & 6 & 0 & 32 & 8 \\
\hline Tetracycline & 18 & 0 & 2 & 5 & 2 & 0.25 \\
\hline Nitrofurantoin & 21 & 2 & 2 & 0 & 64 & 16 \\
\hline Naladixic acid & 19 & 0 & $\overline{1}$ & 5 & 4 & 1 \\
\hline
\end{tabular}

Table IV Reporting of antibiotic sensitivity of $\mathrm{K}$. aerogenes in trial 6 by 25 laboratories 


\begin{tabular}{|c|c|c|c|c|c|c|c|c|c|c|c|c|c|c|c|c|c|c|c|c|c|c|c|}
\hline $\begin{array}{l}\text { Anti- } \\
\text { biotic in } \\
\text { Disc ( } \mu g)\end{array}$ & $P e n^{1}$ & Amp & Met & Clo & $\mathrm{Car}$ & Cep & Cep & str & Kan & $\mathrm{NeO}$ & Gen & Tet & Chl & $\mathrm{Pol}^{1}$ & Col & Ery & $\operatorname{Lin}$ & Clin & Fuc & Nov & $B a c$ & Nit & $\mathrm{Nal}$ \\
\hline 1 & 15 & & & 1 & & & & & & & & & & & & & & & & & & & \\
\hline 2 & 3 & 8 & & & & & & 2 & & & 4 & & & & & 1 & 12 & 12 & & & & & \\
\hline 5 & 5 & 4 & & 5 & & $\begin{array}{l}13 \\
\text { (1) }\end{array}$ & 1 & & 8 & & & 2 & 1 & & & 10 & & & & 9 & 1 & & \\
\hline 10 & & $\begin{array}{c}2 \\
(1)^{2}\end{array}$ & 20 & 1 & & 1 & & $\begin{array}{l}13 \\
\text { (1) }\end{array}$ & & 13 & $\begin{array}{l}17 \\
(10)\end{array}$ & 14 & 7 & & & 11 & 4 & & 21 & & 9 & & \\
\hline 25 & & $\begin{array}{l}9 \\
(15)\end{array}$ & & & 5 & $\begin{array}{c}7 \\
(12)\end{array}$ & $\begin{array}{l}10 \\
(5)\end{array}$ & $\begin{array}{r}6 \\
(5)\end{array}$ & & & & 6 & 7 & & & & & & & & & & \\
\hline 30 & & 1 & & & & & & & $\begin{array}{l}14 \\
(13)\end{array}$ & 3 & (1) & & & & & & & & & 2 & & & \\
\hline .50 & & & & & & & & 2 & & 1 & & 2 & $\begin{array}{r}8 \\
(4)\end{array}$ & (1) & $\begin{array}{l}11 \\
(1)\end{array}$ & 2 & & & & 1 & & 1 & 24 \\
\hline 100 & & & & & $\begin{array}{l}17 \\
(23)\end{array}$ & & & & & & & & & 4 & & & & & & & & & \\
\hline 200 & & & & & & & & & & & & & & 2 & $\begin{array}{c}7 \\
(10)\end{array}$ & & & & & & & 22 & \\
\hline 300 & & & & & & & & & & & & & & $\begin{array}{c}3 \\
(5)\end{array}$ & & & & & & & & & \\
\hline $\begin{array}{l}3,000 \\
\text { Not used }\end{array}$ & 1 & 0 & 4 & 17 & 2 & 3 & 13 & 1 & 2 & 7 & 3 & 0 & 1 & 15 & 6 & 0 & 8 & 12 & 3 & 12 & 14 & 1 & $\begin{array}{l}1 \\
0\end{array}$ \\
\hline
\end{tabular}

Table V Number of laboratories employing paper discs of various potencies for antibiotic sensitivity testing

${ }^{1}$ Units

${ }^{2}$ Where figures are in brackets laboratory has indicated a different strength for use with organisms isolated from urine

\begin{tabular}{|c|c|c|c|c|c|c|c|}
\hline \multicolumn{3}{|c|}{ Direct Sensitivity Testing } & \multicolumn{5}{|c|}{ No. of Colonies Picked for Sensitivity Tests } \\
\hline Routine & Sometimes & No & 1 & $2-4$ & $>5$ & Sweep & Direct Tests Only \\
\hline 14 & 8 & 2 & 10 & 4 & 4 & 4 & 2 \\
\hline
\end{tabular}

Table VI Swab routine in 24 laboratories

\begin{tabular}{|c|c|c|c|c|c|c|c|c|c|c|c|}
\hline \multicolumn{3}{|c|}{ Primary Culture Media } & \multicolumn{3}{|c|}{ Enrichment Broths } & \multicolumn{4}{|c|}{$\begin{array}{l}\text { Number of Colonies of Each Type } \\
\text { Picked for Identification }\end{array}$} & \multicolumn{2}{|c|}{$\begin{array}{l}\text { Control of Performance of } \\
\text { Culture Media }\end{array}$} \\
\hline $\begin{array}{l}\text { Desoxy- } \\
\text { cholate } \\
\text { Citrate }\end{array}$ & $\begin{array}{l}\text { Mac- } \\
\text { Conkey }\end{array}$ & $\begin{array}{l}\text { Wilson and } \\
\text { Blair }\end{array}$ & Selenite & $\begin{array}{l}\text { Tetra- } \\
\text { thionate }\end{array}$ & Rappaport & 1 & $2-5$ & 10 & $\begin{array}{l}\text { Serology } \\
\text { Positive }\end{array}$ & Regular & Sometimes None \\
\hline 24 & 16 & 5 & 24 & 5 & 4 & 15 & 6 & 1 & 2 & 8 & 7 \\
\hline
\end{tabular}

Table VII Laboratory routine for faeces in 24 laboratories employing various techniques

\begin{tabular}{|c|c|c|c|c|c|c|c|c|}
\hline \multicolumn{5}{|c|}{ Quantitative Procedure Employed } & \multicolumn{4}{|c|}{ Nature of Specimens Accepted } \\
\hline None & Dip Slide & $\begin{array}{l}\text { Blotting } \\
\text { Paper }\end{array}$ & $\begin{array}{l}\text { Standard } \\
\text { Loop }\end{array}$ & $\begin{array}{l}\text { Modified Miles and } \\
\text { Misra Viable Count }\end{array}$ & $\begin{array}{l}\text { Fresh or } \\
\text { Refrigerated }\end{array}$ & $\begin{array}{l}\text { Insist on a Fresh } \\
\text { Specimen }\end{array}$ & $\begin{array}{l}\text { Same } \\
\text { Day }\end{array}$ & $\begin{array}{l}\text { All } \\
\text { Processed }\end{array}$ \\
\hline 1 & 6 & 7 & 12 & 6 & 8 & $12^{1}$ & 2 & 2 \\
\hline
\end{tabular}

Table VIII Urine routine in 24 laboratories

${ }^{1}$ Two laboratories insisted but not rigidly

any worse than those picking more, in this small sample.

Table VIII shows the quantitative routine used for urines. Despite much criticism of 'standard loops' in the past the use of such a loop was the most popular quantitative method, most laboratories made some attempt to obtain a fresh specimen of urine on which to perform their quantitative routine. 
of reports for analysis in the different trials. It is of course equally important to put work through a laboratory when the director is away as when he is present, and most routine work is dealt with within 48 hours of receipt. Some delay in our trial arose because laboratories performed 'phage typing on staphylococci and serology on salmonellae but in those circumstances as in clinical practice an interim report should have been sent. Specimens were usually posted on Tuesdays, and, even allowing for the postal services must have been received by Friday in all but the most exceptional circumstances, we would therefore have expected to receive all the results by the end of the following week. Using the computer for the tables would have then meant returning results to participants within 14 days of the initial receipt of the specimens. In the last three trials when detailed records were kept there were signs of improvement as in trial 4, seven laboratories, trial 5, five laboratories, and trial 6 only two laboratories submitted results later than the twelfth day after specimens had been posted to them.

The object of quality control is to improve performance but these trials are not sufficiently extensive to be able to assess improvement satisfactorily. It appears from Table I that there was some improvement in the isolation of salmonella from faeces, especially in hospital laboratories, but with the exception of improvement in testing Pseudomonas sensitivity to carbenicillin and perhaps a little improvement in the recognition of methicillinresistant Staph. aureus there was no appreciable difference in performance in the later trials.

It might have been expected that the false reports of sensitivity of Strept. faecalis to ampicillin (Table III) was due to the use of high content discs but this cannot have been the only factor since seven laboratories reporting sensitivity were using $2 \mu \mathrm{g}$ discs for all tests. Ten laboratories reported further tests of sensitivity to antibiotic combinations, notably penicillin with streptomycin. In these circumstances even a preliminary report of sensitivity to ampicillin may be dangerous as treatment with this drug in normal dosage will not succeed in Strept. faecalis endocarditis.
There was evidence of lack of knowledge of the normal resistance of species to antibiotics: for example, one laboratory identified Proteus mirabilis correctly and reported it sensitive to colistin. Another reported Klebsiella in urine sensitive to fusidic acid. A further correct report of an unnecessary test was Pseudomonas in urine resistant to methicillin.

These trials had the advantage that there were few participants who could meet and discuss results and this probably played a large part in bringing particular faults to the notice of directors who could then discuss remedies for them. In a comprehensive service this would not be possible and some substitute for it, perhaps a quarterly bulletin from manufacturers of specimens and assessors is desirable. This need not interfere with anonymity which should be maintained.

The results show that quality control by sending known positive specimens brings to light a wide variety of errors. In all tests, except sensitivity of Strept. faecalis to ampicillin, most of the results were correct. Extra tests of validity undertaken by the manufacturer of specimens and other participants in these trials would probably not be needed in a comprehensive service.

We thank Mrs J. N. Blair for writing the computer programme and handling computer data and Miss P. M. Waterworth for estimating the MICs of antimicrobials for the bacteria sent.

\section{References}

Association of Clinical Pathologists (1965). Report on antibiotic sensitivity test trial organized by the Bacteriology Committee of the Association of Clinical Pathologists. J. clin. Path., 18, $1-5$.

College of Pathologists of Australia (1968). Report: Microbiology Survey, No. 7, p. 37.

Hewitt, J. H., Coe, A. W., and Parker, M. T. (1969). The detection of methicillin resistance in Staphylococcus aureus. J. med. Microbiol., 2, 443-456.

Waterworth, P. M. (1969). Interpretation of disc sensitivity tests on organisms of intermediate sensitivity. J. med. Lab. Technol., 26, $106-110$

Whitby, J. L., and Blair, J. N. (1970). A computer linked data processing system for routine hospital bacteriology. Soc. appl. Bact. Technol., Ser. No. 4, p. 23. 